\title{
Sentinel-2 images for effective mapping of soil salinity in agricultural fields
}

\author{
Khalid A. Al-Gaadi ${ }^{1,2}$, ElKamil Tola ${ }^{1,2}$, Rangaswamy Madugundu ${ }^{1, *}$ and \\ Ronnel B. Fulleros ${ }^{2}$ \\ ${ }^{1}$ Precision Agriculture Research Chair, Deanship of Scientific Research, King Saud University, Riyadh 11451, Saudi Arabia \\ ${ }^{2}$ Department of Agricultural Engineering, College of Food and Agriculture Sciences, King Saud University, Riyadh 11451, Saudi Arabia
}

\begin{abstract}
Salinity is a critical feature for the management of agricultural soil, particularly in arid and semi-arid areas. The present study was conducted to develop an effective soil salinity prediction model using Sentinel2A (S2) satellite data. Initially, the collected soil samples were analysed for soil salinity $\left(\mathrm{EC}_{\mathrm{e}}\right)$. Subsequently, multiple linear regression analysis was carried out between the obtained $\mathrm{EC}_{\mathrm{e}}$ values and $\mathrm{S} 2$ data, for the prediction of soil salinity models. The relationship between $\mathrm{EC}_{\mathrm{e}}$ and $\mathrm{S} 2$ data, including individual bands, band ratios and spectral indices showed moderate to highly significant correlations $\left(R^{2}=0.43-0.83\right)$. A combination of SWIR-1 band and the simplified brightness index was found to be the most appropriate $\left(R^{2}=0.65 ; P<0.001\right)$ for prediction of soil salinity. The results of this study demonstrate the ability to obtain reliable estimates of $\mathrm{EC}$ using $\mathrm{S} 2$ data.
\end{abstract}

Keywords: Agricultural lands, multiple linear regression, satellite data simplified brightness index, soil salinity.

SoIL salinity is considered as one of the major soil characteristics affecting the interaction between plants and soil in addition to its significant impact on the availability of soil nutrients and thus affecting crop production $^{1,2}$. Salinity is also an important factor with respect to sustainable agriculture and soil management, especially in arid and semi-arid regions. However, some agricultural practices contribute significantly to the salinization of agricultural lands such as irregular irrigation, use of saltwater and application of agrichemicals ${ }^{3}$. Corwin and Lesch $^{4}$ reported that about 50\% (250 million hectares; $\mathrm{m} \mathrm{ha}$ ) of the irrigated soil around the world is adversely affected by soil salinity; of which, about $20 \mathrm{~m}$ ha is severely affected.

Electrical conductivity (EC) is closely related to the composition and concentration of dissolved salts in soil solution, and therefore EC of the soil saturation extract $\left(\mathrm{EC}_{\mathrm{e}}\right)$ is used as a standard measure of soil salinity (expressed in $\mathrm{mS} / \mathrm{cm}$ or $\mathrm{dS} / \mathrm{m})^{5,6}$. The commonly accepted range of soil salinity indicates that a soil with $\mathrm{EC}_{\mathrm{e}}$ greater than $4 \mathrm{dS} / \mathrm{m}$ at $25^{\circ} \mathrm{C}$ is defined as saline soil and that with

*For correspondence. (e-mail: rmadugundu@ksu.edu.sa)
$\mathrm{EC}_{\mathrm{e}}$ greater than $15 \mathrm{dS} / \mathrm{m}$ as strongly saline soil ${ }^{7}$. Although soil salinity mapping by conventional methods, such as field surveys and laboratory analysis is accurate, such methods are time-consuming, costly and labourintensive, especially for large-scale measurements. However, advanced technologies such as proximal sensing (EM38 survey, Geonics Limited, Canada) and remote sensing (satellite images) methods, support EC mapping and provide accurate information regarding salt-affected areas. In this context, the potential satellite datasets and image analysis techniques have contributed to the accurate and economic mapping of soil salinity ${ }^{8,9}$ and multispectral satellite images such as MODIS ${ }^{10}$, Landsat $\mathrm{TM}^{11}$, Landsat $\mathrm{ETM}^{+}$(refs 12, 13), Landsat-8 (refs 14, 15), IKONOS $^{16,17}$, WorldView ${ }^{18}$, and Sentinel-2 (ref. 19) have been widely used for mapping soil salinity.

Various salinity indicators have been derived from satellite imagery and used to identify salt-affected agricultural areas ${ }^{20-22}$. The basis of these indicators is the spectral behaviour of saline soils captured by multispectral images ${ }^{23}$. As direct salinity indicators, indices such as brightness index (BI), normalized difference salinity index (NDSI) and salinity index (SI) have been developed and commonly used to identify salt-affected areas ${ }^{24}$. As indirect salinity indicators, however, vegetation indices (VIs) such as the normalized difference vegetation index (NDVI), enhanced vegetation index (EVI), soil adjusted vegetation index (SAVI) and green difference vegetation index (GDVI) have been widely used for soil salinity assessment and mapping ${ }^{21,25,26}$. A wide range of regression models such as linear and exponential regression ${ }^{2}$, ordinary least square and spatial regression ${ }^{27}$, and partial least square regression ${ }^{28}$ have been used as tools to retrieve soil salinity.

Given the negative impact of saline soils on agricultural practices and ultimately on crop production, it is necessary to maintain soil quality and reclaim saline soils, particularly in arid regions such as Saudi Arabia ${ }^{16}$. In this regard, continuous monitoring of soil salinity in agricultural fields is important. Therefore, the main objective of the present study was to develop satellite-based models for monitoring soil salinity in agricultural fields under arid climatic conditions of Saudi Arabia, using remotely sensed Sentinel-2A (S2) multispectral data. 


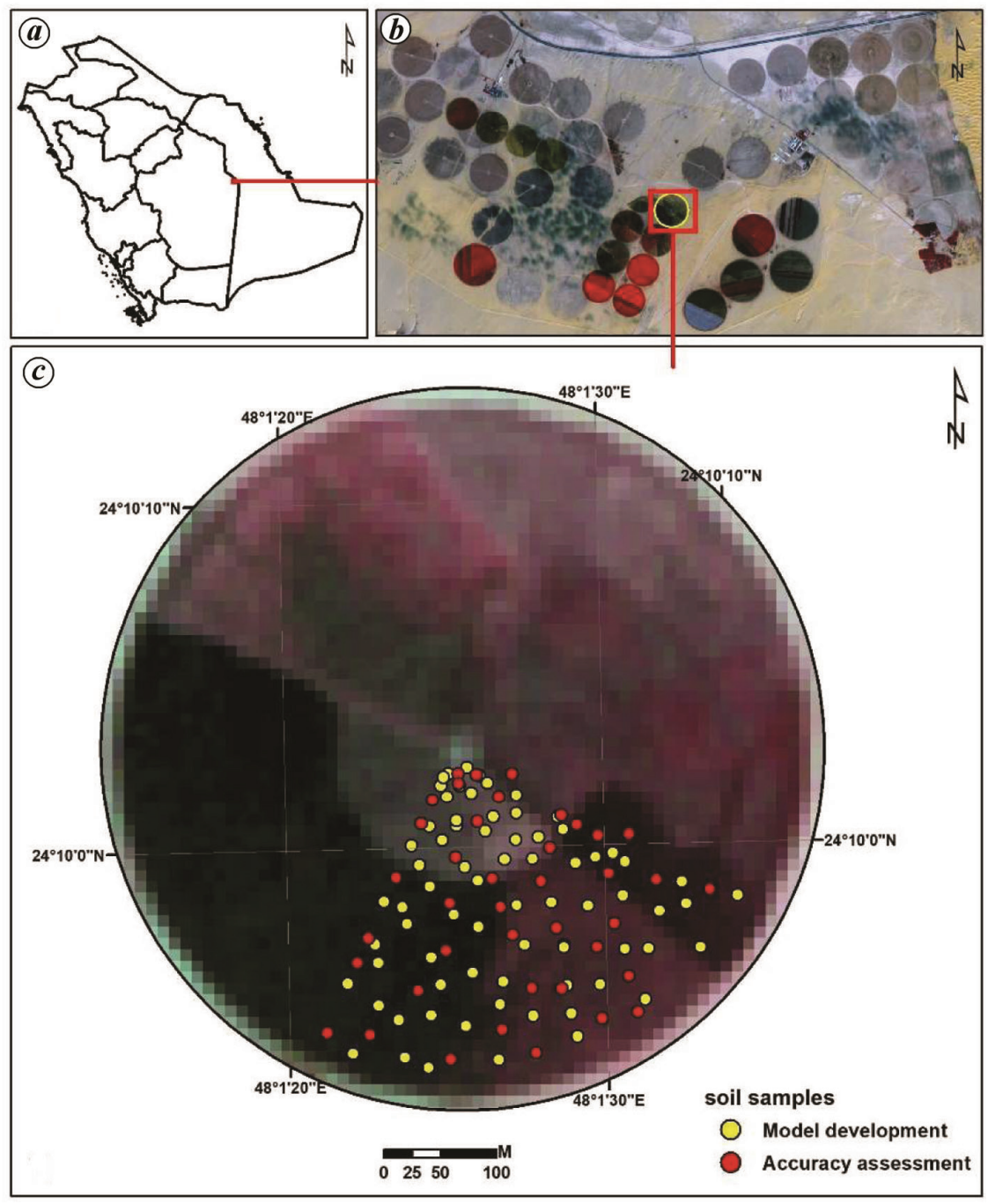

Figure 1. Location map of the study site: (a) Kingdom of Saudi Arabia, (b) Tawdeehiya Farms, and (c) Experimental field-ID: N8.

\section{Materials and methods}

\section{Study area}

The experiment was conducted on a 27 ha bare soil field (pivot ID: N8) of Tawdeehiya Farms in the Al-Kharj

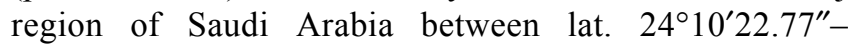
$24^{\circ} 12^{\prime} 37.25^{\prime \prime} \mathrm{N}$ and the long. $47^{\circ} 56^{\prime} 14.60^{\prime \prime}-48^{\circ} 05^{\prime} 08.56^{\prime \prime} \mathrm{E}$ (Figure 1). The soil in the experimental farm is mainly characterized as sandy loam and the major crops cultivated were alfalfa, Rhodes grass and carrot. The average annual minimum and maximum temperature was $12^{\circ} \mathrm{C}$ (winter) and $42^{\circ} \mathrm{C}$ (summer) respectively. The average annual rainfall was $\sim 98 \mathrm{~mm}$, distributed mainly between November and February.

\section{Soil sampling and laboratory analysis of soil salinity}

One-quarter $(\approx 6.75 \mathrm{ha})$ of field N8 (Figure $1 c$ ) was allocated as an experimental section for the development of soil salinity prediction model. In the first phase of the experiment, a total of 113 composite soil samples were randomly collected from the topsoil $(0-25 \mathrm{~cm}$ depth) of the field. Selection of soil sampling depth was based on the fact that plant roots, biological and nutrient activities occur mainly in the topsoil $(0-25 \mathrm{~cm})$, and hence crop response is high within this layer ${ }^{29-32}$.

The samples were randomly collected from the experimental field and analysed in the laboratory for soil $\mathrm{EC}_{\mathrm{e}}$ and used for the calibration/testing of prediction models. While $65 \%$ of the collected soil samples (i.e. 73 samples) was used for calibration, the remaining $35 \%$ (i.e. 40 samples) was earmarked for accuracy assessment of the developed soil salinity prediction models (Figure $1 c$ ). A hand-held GPS receiver (Trimble GeoXH) was used for geographical attribution of the sampling locations. Five soil sub-samples were taken around each sampling point within a circle of $10 \mathrm{~m}$ radius from the centre (i.e. the stored GPS location) with a sample size of $10 \mathrm{~m}$ pixel, corresponding to S2 visible-band resolution. These 
Table 1. Spectral and vegetation indices used in soil salinity mapping

\begin{tabular}{|c|c|c|}
\hline Index & Formula & Reference \\
\hline Salinity index $x_{1}$ & $\mathrm{SI}_{1}=\sqrt{\rho_{\text {Green }} \times \rho_{\text {Red }}}$ & 33 \\
\hline Salinity index ${ }_{2}$ & $\mathrm{SI}_{2}=\sqrt{\rho_{\text {Green }}^{2} \times \rho_{\text {Red }}^{2}+R_{\mathrm{NIR}}^{2}}$ & \\
\hline Salinity index $x_{3}$ & $\mathrm{SI}_{3}=\sqrt{\rho_{\text {Green }}^{2} \times \rho_{\text {Red }}^{2}}$ & \\
\hline Salinity index ${ }_{4}$ & $\mathrm{SI}_{4}=\rho_{\mathrm{Red}} / \rho_{\mathrm{NIR}}$ & 33 \\
\hline Salinity index $x_{11}$ & $\mathrm{SI}_{11}=\rho_{\mathrm{SWIR} 1} / \rho_{\mathrm{SWIR} 2}$ & 34 \\
\hline Intensity $_{1}$ & $\mathrm{INT}_{1}=\left(\rho_{\text {Green }}+\rho_{\text {Red }}\right) / 2$ & 33 \\
\hline Intensity $_{2}$ & $\mathrm{INT}_{2}=\left(\rho_{\text {Green }}+\rho_{\text {Red }}+\rho_{\text {NIR }}\right) / 2$ & \\
\hline Simplified brightness index & $\mathrm{SBI}=\sqrt{\rho_{\text {Green }}^{2}+\rho_{\mathrm{NIR}}^{2}}$ & 24 \\
\hline Normalized difference & $\mathrm{NDSI}=\left(\rho_{\mathrm{Red}}-\rho_{\mathrm{NIR}}\right) /\left(\rho_{\mathrm{Red}}-\rho_{\mathrm{NIR}}\right)$ & 24 \\
\hline \multicolumn{3}{|l|}{ Salinity index } \\
\hline Vegetation soil salinity & $\mathrm{VSSI}=2 \times \rho_{\text {Green }}-\left(5 \times\left(\rho_{\text {Red }}+\rho_{\mathrm{NIR}}\right)\right)$ & 38 \\
\hline \multicolumn{3}{|l|}{ Index } \\
\hline NIR SWIR salinity index & $\mathrm{NSI}=\frac{\left(\rho_{\mathrm{SWIR} 1}-\rho_{\mathrm{SWIR} 2}\right)}{\left(\rho_{\mathrm{SWIR} 1}-\rho_{\mathrm{NIR}}\right)}$ & 39 \\
\hline Soil adjusted vegetation index; $L=0.5$ & $\mathrm{SAVI}=(1+L) \times\left(\frac{\rho_{\mathrm{NIR}}-\rho_{\mathrm{Red}}}{L+\rho_{\mathrm{NIR}}+\rho_{\mathrm{Red}}}\right)$ & 40 \\
\hline
\end{tabular}

Note: $\rho$ is the soil reflectance. Subscripts Blue, Green, Red, NIR, SWIR1 and SWIR2 represent the Sentinel-2A bands.

sub-samples were then mixed, air-dried, ground, passed through a 2-mm sieve and analysed in the laboratory for $\mathrm{EC}_{\mathrm{e}}(\mathrm{dS} / \mathrm{m})$.

\section{Remote sensing data}

Sentinel-2A image scene (ID: T38QRM of 9/12/2018) was downloaded from the USGS Earth Explorer (https://earthexplorer.usgs.gov) coinciding with the field samples. Sentinel Application Platform (SNAP) developed by the European Space Agency (https://step.esa.int/ main/download/snap-download/) was used for image analysis. The SNAP is a free software program especially designed for the analysis of Sentinel images. The images were geo-rectified to the Universal Transverse Mercator (UTM) coordinate system using the World Geodetic System (WGS) 1984 datum assigned to the north UTM zone 38. The region of interest (ROI), pertaining to the experimental field was extracted for further analysis. The raw image was processed for bottom-of-reflectance, clipped to the study area and was subsequently used in conjunction with a set of spectral bands to calculate the salinity index (SI), intensity index (INT) and simplified brightness index (BI) as illustrated in Table 1.

\section{Modelling and soil EC mapping}

Figure 2 shows the methodology adopted in this study. The acquired S2 images were analysed and used for com- putation of salinity and vegetation indices. Regression analysis was performed for the development of soil EC prediction models using the laboratory analysed soil EC (i.e. $\mathrm{EC}_{\mathrm{e}}$ ) against multiple variables, including the individual S2 bands and spectral indices as given in Table 1.

Simple and multiple linear regression methods were applied to develop relationships between the laboratorydetermined soil $\mathrm{EC}_{\mathrm{e}}$ (as a dependent variable) and the $\mathrm{S} 2$ extracted datasets, including individual spectral bands, band ratios and spectral indices (as independent variables). Linear regression (multivariate and stepwise) analysis was carried out using the SPSS statistical software program (Ver. 20). The performance of the developed models was tested using $R^{2}$ values, standard errors, and $P$-values. The best-performed regression model was chosen for prediction and mapping of soil EC in the agricultural fields of the experimental farm.

\section{Cross-validation of the developed soil salinity prediction models}

Statistical performance indicators, including coefficient of determination $\left(R^{2}\right)$, mean bias error (MBE), and root mean square error (RMSE) were used to examine how accurately the models predict soil salinity $\left(\mathrm{EC}_{\mathrm{P}}\right)$ compared to $\mathrm{EC}_{\mathrm{e}}$ values. In this regard, 40 soil samples were randomly allocated for accuracy assessment of the developed salinity models and analysed in the laboratory for 
$\mathrm{EC}_{\mathrm{e}}$. The three performance indicators used were computed according to eqs (1)-(3) below.

$$
\begin{aligned}
& \mathrm{RMSE}=\sqrt{\frac{1}{n} \sum_{i=1}^{n}\left(y_{i}-\hat{y}_{i}\right)^{2},} \\
& R^{2}=1-\frac{\sum_{i=1}^{n}\left(y_{i}-\hat{y}_{i}\right)^{2}}{\sum_{i=1}^{n}\left(y_{i}-\bar{y}_{i}\right)^{2}}, \\
& \mathrm{MBE}=\frac{1}{n} \sum_{i=1}^{n}\left(y_{i}-\hat{y}_{i}\right),
\end{aligned}
$$

where $\hat{y}_{i}$ is the observed EC, $y_{i}$ the predicted EC and $\bar{y}_{i}$ is the mean value of observed EC.

\section{Results and discussion}

Table 2 summarizes field observations of the experiment. The recorded EC ranged between 2.88 and $3.97 \mathrm{dS} / \mathrm{m}$, with a mean value of $3.12 \mathrm{dS} / \mathrm{m}$. During the time of soil sampling, soil $\mathrm{pH}$ ranged between 7.15 and 7.29 and the mean soil moisture was $9.77 \%$.

Table 2. Summary of observations from the experimental field

\begin{tabular}{lcccc}
\hline Field ID & Soil type & $\begin{array}{c}\text { Electrical } \\
\text { conductivity } \\
\left(\mathrm{dS} \mathrm{m}^{-1}\right)\end{array}$ & $\mathrm{pH}$ & $\begin{array}{c}\text { Soil } \\
\text { moisture (\%) }\end{array}$ \\
\hline N8 & Sandy loam & 3.12 & 7.22 & 9.77 \\
\hline
\end{tabular}

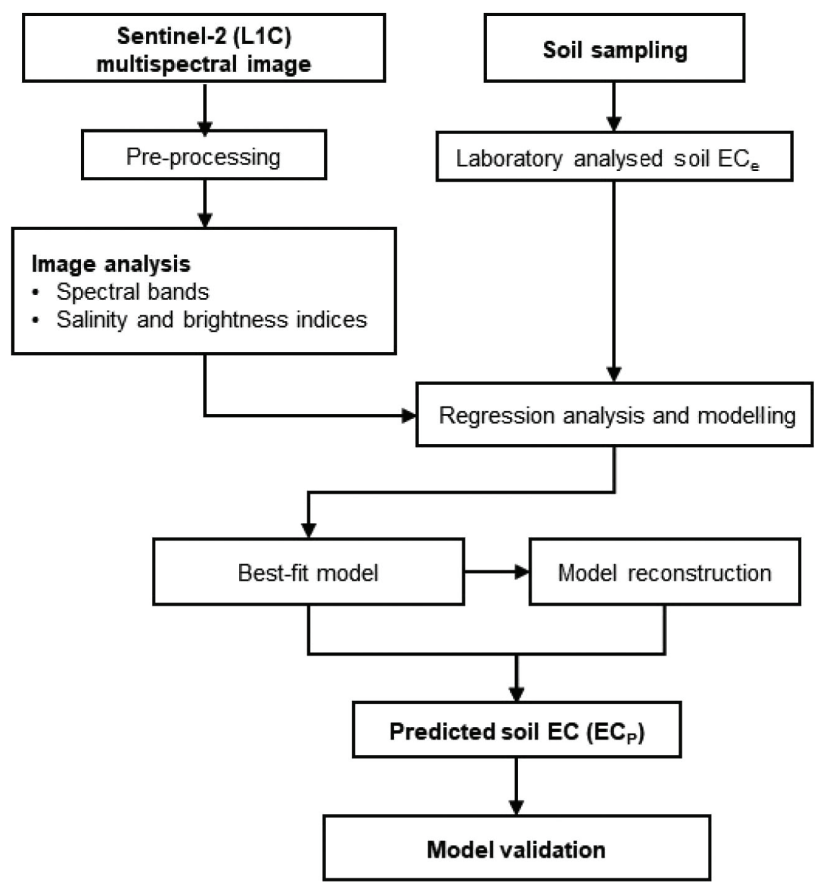

Figure 2. Flowchart of soil salinity modelling and mapping.
Soil EC prediction models: regression analysis and selection of variables

Table 3 shows regression analysis results describing the relationship between soil EC as an independent variable and the dependent variables (individual bands of S2 and spectral indices of S2 products). Although there was some heterogeneity at different locations, the SWIR-1 band of the S2 image and SBI were considered as the most useful variables for prediction of soil EC in the experimental field. Based on the obtained regression results (Table 3), the S2 SWIR1 band and SBI variables were used in the development of $\mathrm{EC}_{\mathrm{P}}$ models. On the basis of multiple linear regression results, the obtained three soil EC prediction models are given in eqs (4)-(6) representing model-1, model-2 and model-3 respectively. Table 4 shows the performance of the three developed models as indicated by the accuracy of the results.

$$
\begin{aligned}
& \mathrm{EC}_{\mathrm{P}}=[2.961 * \mathrm{SWIR} 1+2.070], \\
& \mathrm{EC}_{\mathrm{P}}=[3.076 * \mathrm{SBI}+1.797], \\
& \mathrm{EC}_{\mathrm{P}}=[(2.148 * \mathrm{SBI})+(0.912 * \mathrm{SWIR} 1)+1.872] .
\end{aligned}
$$

The statistical analysis results presented in Table 4 reveal that model-3 is robust for the prediction of $\mathrm{EC}_{\mathrm{P}}$ with an $R^{2}$ value of 0.67 and $P<0.001$, compared to the other two models. Although model-3 shows the highest $R^{2}$ value (0.67), the testing results of the models indicate that the MBE value for model-3 $\left(-0.19 \mathrm{dS} \mathrm{m}^{-1}\right)$ is slightly high compared to model-1 $\left(-0.16 \mathrm{dS} \mathrm{m}^{-1}\right)$. For model-1 and model-2, the relationship is found to be moderate with an $R^{2}$ value of 0.65 in training the model. However, model-2 shows low performance during cross-validation $\left(R^{2}=0.54 ; P=0.002\right)$. A similar trend has been reported in earlier studies. For example, Douaoui et al. ${ }^{33}$ evaluated the correlation between the measured soil EC and salinity indices (SI1, SI2 and SI3), and obtained low correlation with $R^{2}$ value of $0.50,0.44$ and 0.49 respectively. Bannari et $a l^{34}$ also found low correlation with SI1 $\left(R^{2}=0.47\right)$, SI2 $\left(R^{2}=0.36\right)$ and SI3 $\left(R^{2}=0.47\right)$. The results of model3 , however, indicate that a combination of the SWIR-1 band and SBI as predictor variables resulted in better prediction accuracy. The same conclusion was drawn by Meti et $a l .{ }^{35}$, with $R^{2}$ value in the range $0.48-0.49$. Taghadosi et al. ${ }^{19}$ reported an $R^{2}$ value of $87.42 \%$ for the combination of all S2 bands along with salinity indicators. Hihi et $a l^{36}$ reported $R^{2}$ value of $48 \%$ with the combination of multiband and SI in the prediction of soil EC. Allbed et al. ${ }^{16}$ reported a relatively good relationship $\left(R^{2}=0.65\right)$ in predicting soil EC using multiple bands of IKONOS data. In a study by Samra and $\mathrm{Ali}^{37}$, the accuracy of the $\mathrm{EC}_{\mathrm{P}}$ models was enhanced $\left(R^{2}=0.73\right)$ by a combination of the reflectance bands and spectral indices. 
Table 3. Regression analysis - laboratory analysed soil EC $\left(E_{e}\right)$ versus Sentinel-2A bands and selected indices

\begin{tabular}{|c|c|c|c|c|c|}
\hline \multirow[b]{2}{*}{ Parameter } & \multicolumn{2}{|c|}{ Sentinel-2A bands } & \multirow[b]{2}{*}{ Parameter } & \multicolumn{2}{|c|}{ Sentinel-2A band ratios/indices } \\
\hline & Modelling & Accuracy & & Modelling & Accuracy \\
\hline B2 (Blue) & $0.25^{\mathrm{NS}}$ & $0.05^{\mathrm{NS}}$ & SI-1 & $0.53^{\mathrm{NS}}$ & $0.41^{\mathrm{NS}}$ \\
\hline B3 (Green) & $0.58^{\mathrm{NS}}$ & $0.44^{\mathrm{NS}}$ & SI-2 & $0.46^{\mathrm{NS}}$ & $0.54^{\mathrm{NS}}$ \\
\hline B4 (Red) & $0.63 *$ & $0.58 *$ & SI-3 & $0.14^{\mathrm{NS}}$ & $0.41 *$ \\
\hline B5 (RedEdge-1) & $0.65 *$ & $0.57 *$ & SI-4 & $0.63 *$ & $0.58 *$ \\
\hline B6 (RedEdge-2) & $0.65 *$ & $0.58 *$ & SI-11 & $0.60 *$ & $0.47^{*}$ \\
\hline B7 (RedEdge-3) & $0.66^{\mathrm{NS}}$ & $0.59 *$ & INT-1 & $0.63 *$ & $0.56^{*}$ \\
\hline B8 (NIR) & $0.64 *$ & $0.57 *$ & INT-2 & $0.39^{\mathrm{NS}}$ & $0.26^{\mathrm{NS}}$ \\
\hline B8A (RedEdge-4) & $0.65 *$ & $0.58 *$ & SBI & $0.65 * *$ & $0.54 * *$ \\
\hline B9 (WA) & $0.57^{\mathrm{NS}}$ & $0.56^{\mathrm{NS}}$ & NDSI & $0.39^{\mathrm{NS}}$ & $0.26^{\mathrm{NS}}$ \\
\hline B10 (Cirrus) & $0.18^{\mathrm{NS}}$ & $0.05^{\mathrm{NS}}$ & SAVI & $0.64^{\mathrm{NS}}$ & $0.56^{\mathrm{NS}}$ \\
\hline B11 (SWIR-1) & $0.65 * *$ & $0.58 * *$ & VSSI & $0.63 *$ & $0.58 *$ \\
\hline B12 (SWIR-2) & $0.61 * *$ & $0.57 * *$ & NSI & $0.43^{\mathrm{NS}}$ & $0.30^{\mathrm{NS}}$ \\
\hline
\end{tabular}

*Significant at 0.05 level; **Significant at 0.01 level; NS, Not significant.

Table 4. Performance of developed soil EC $\left(\mathrm{EC}_{\mathrm{P}}\right)$ prediction models

\begin{tabular}{llccc}
\hline Model & Training/test & $R^{2}$ & $\begin{array}{c}\text { Root mean square error } \\
\left(\mathrm{RMSE} ; \mathrm{dS} \mathrm{m} \mathrm{C}^{-1}\right)\end{array}$ & $\begin{array}{c}\text { Mean bias error } \\
\left(\mathrm{MBE} ; \mathrm{dS} \mathrm{m}^{-1}\right)\end{array}$ \\
\hline M1 & Training & $0.65^{* *}$ & - & - \\
& Test & $0.58^{* *}$ & 0.13 & -0.16 \\
\multirow{2}{*}{ M2 } & Training & $0.65^{* *}$ & - & - \\
& Test & $0.54^{* *}$ & 0.14 & -0.24 \\
\multirow{2}{*}{ M3 } & Training & $0.67^{* *}$ & - & - \\
& Test & $0.59^{* *}$ & 0.21 & -0.19 \\
\hline
\end{tabular}

**Significant at 0.01 level.

Table 5. Multiple linear regression analysis $-\mathrm{EC}_{\mathrm{p}}$ versus laboratory analysed soil $\mathrm{EC}_{\mathrm{e}}$

\begin{tabular}{lccccr}
\hline & \multicolumn{2}{c}{ RMSE } & \multicolumn{2}{c}{ MBE } \\
\hline Model & $R^{2}$ & $\left(\mathrm{dS} \mathrm{m}^{-1}\right)$ & $(\%)$ & $\left(\mathrm{dS} \mathrm{m}^{-1}\right)$ & $(\%)$ \\
\hline 1 & $0.44^{*}$ & 1.09 & 14.34 & 1.25 & -17.29 \\
2 & $0.54^{*}$ & 0.94 & 10.61 & 1.08 & -14.22 \\
3 & $0.62^{*}$ & 0.86 & 10.02 & 0.92 & 6.66 \\
\hline
\end{tabular}

*Significant at 0.05 level.

Table 6. Descriptive statistics of soil EC maps

\begin{tabular}{lcccc}
\hline & \multicolumn{2}{c}{ Agricultural fields - soil EC $\left(\mathrm{dS} \mathrm{m}^{-1}\right)$} & \\
\cline { 2 - 4 } Model & Minimum & Maximum & Mean & Standard deviation \\
\hline M1 & 1.8 & 2.9 & 2.3 & 0.04 \\
M2 & 2.0 & 3.6 & 3.2 & 0.12 \\
M3 & 2.1 & 3.7 & 2.9 & 0.08 \\
\hline
\end{tabular}

\section{Application of the developed models to other fields} in the experimental farm

Accuracy evaluation of the developed models was carried out using laboratory-measured soil samples taken from the experimental field (N8), other than the samples that were used in the development of the models. Table 5 shows the statistical significance of the models. A soil salinity map of the entire experimental farm was generated, for the S2 image of 9 December 2018, based on the three prediction models (Figure 3). The soil EC map of agricultural fields in the experimental farm generated based on three models showed that the mean soil EC of the farm ranged between 1.8 and $4.2 / \mathrm{dS} \mathrm{m}$. As observed from Table 6, model-3 shows the best reliable soil EC values in the experimental farm with an average value of 2.9 $( \pm 0.08) \mathrm{dS} / \mathrm{m}$ compared to the maps from model-1 $(2.3 \pm 0.04 \mathrm{dS} / \mathrm{m})$ and model-2 $(2.9 \pm 0.12 \mathrm{dS} / \mathrm{m})$.

\section{Conclusion}

Salinity is an important factor for the sustainable management of soil and water resources, especially in arid and semi-arid areas as in Saudi Arabia. Therefore, this study was conducted to employ multiple regression modelling for the estimation of soil salinity using S2 satellite images. The generated models show satisfactory results in predicting soil EC. The following are specific conclusions:

- Multiple regression modelling permits reliable estimations of soil EC using S2 data.

CURRENT SCIENCE, VOL. 121, NO. 3, 10 AUGUST 2021 

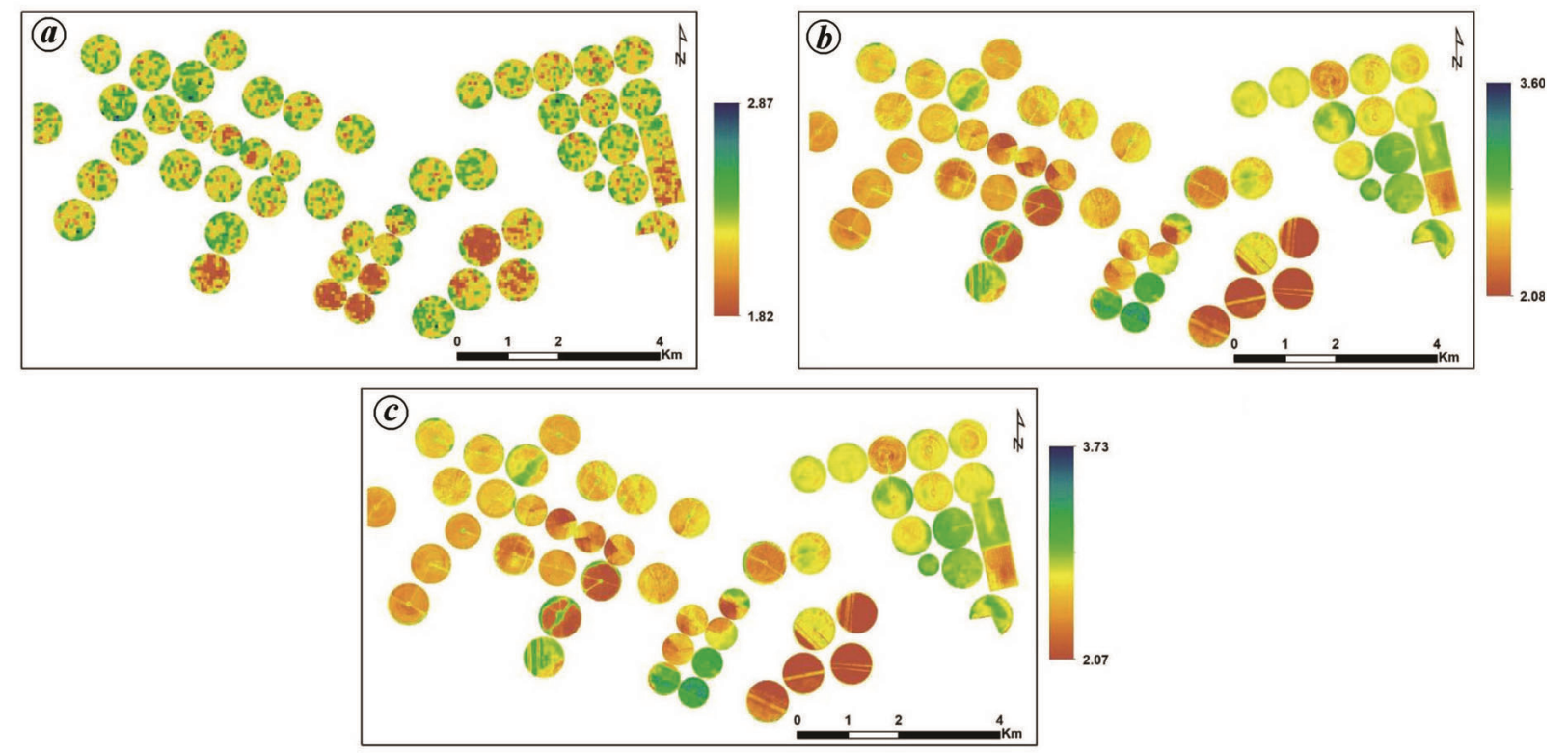

Figure 3. Soil salinity map of the entire experimental farm generated with the obtained prediction models: $(\boldsymbol{a})$ model-3, (b) model-2 and (c) model-1.

- The SWIR-1 band and SBI were found to be good indicators for the prediction of soil EC.

- Three models were found to be accurate in $\mathrm{EC}_{\mathrm{P}}$ from S2 data. Among these, model-3, a combination of the SWIR-1 band and SBI, exhibited the most accurate values of soil $\mathrm{EC}_{\mathrm{P}}\left(R^{2}=0.67 ; P<0.001\right)$.

Conflict of interest: The authors declare no conflict of interest.

1. Asfaw, E., Suryabhagavan, K. V. and Argaw, M., Soil salinity modeling and mapping using remote sensing and GIS: the case of Wonji sugar cane irrigation farm, Ethiopia. J. Saudi Soc. Agric. Sci., 2016, 17(3), 250-258; https://doi.org/10.1016/j.jssas. 2016.05.003.

2. Gorji, T., Sertel, E. and Tanik, A., Monitoring soil salinity via remote sensing technology under data scarce conditions: a case study from Turkey. Ecol. Indic., 2017, 74, 384-391; https:// doi.org/10.1016/j.ecolind.2016.11.043.

3. Gorji, T., Tanik, A. and Sertel, E., Soil salinity prediction, monitoring and mapping using modern technologies. Procedia. Earth Planet. Sci., 2015, 15, 507-512; https://doi:10.1016/j.proeps. 2015.08.062.

4. Corwin, D. and Lesch S., Application of soil electrical conductivity to precision agriculture. Agron. J., 2003, 95(3), 455-471; https:// doi:10.2134/agronj2003.0455.

5. Rhoades, J. D., Chanduvi, F. and Lesch, S., Determination of soil salinity from aqueous electrical conductivity. In Soil Salinity Assessment - Methods and Interpretation of Electrical Conductivity Measurements. FAO Irrigation and Drainage Paper 57, Food and Agriculture Organization of the United Nations, Rome, Italy, 1999, ISBN: 92-5-104281-0; http://www.fao.org/3/x2002e/ x2002e.pdf.

6. Grisso, R., Alley, M., Wysor, W. G., Holshouser, D. and Thomason, W., Precision Farming Tools: soil Electrical Conductivity. Virginia Cooperative Extension Publication, USA, 2009, pp. 442-
508; https://vtechworks.lib.vt.edu/bitstream/handle/10919/51377/ 442508.pdf? sequence $=1$ \&isAllowed $=\mathrm{y}$

7. Shahid, S. A. and Khalil-ur-Rahman, Soil salinity development, classification, assessment and management in irrigated agriculture. In Handbook of Plant and Crop Stress (ed. Pessarakli, M.), CRC Press, Taylor \& Francis Group, Boca Raton, Florida, USA, 2011, pp. $23-40$.

8. Eldeiry, A. and Garcia L. A., Detecting soil salinity in alfalfa fields using spatial modeling and remote sensing. Soil Sci. Soc. Am. J., 2008, 72(1), 201-211; https://doi:10.2136/sssaj2007. 0013.

9. Morshed, M. M., Islam, M. T. and Jamil, R., Soil salinity detection from satellite image analysis: an integrated approach of salinity indices and field data. Environ. Monitor. Assess., 2016, 188(2); 119; https://doi:10.1007/s10661-015-5045-x.

10. Zhang, T. T., Qi, J. G., Gao, Y., Ouyang, Z. T., Zeng, S. L. and Zhao, B., Detecting soil salinity with MODIS time series VI data. Ecol Indic., 2015, 52, 480-489; https://doi.org/10.1016/j.ecolind. 2015.01.004.

11. Elnaggar, A. A. and Noller, J. S., Application of remote-sensing data and decision-tree analysis to mapping salt-affected soils over large areas. Remote Sensing, 2010, 2(1), 151-165; https://doi.org/ $10.3390 /$ rs2010151.

12. Katawatin, R. and Kotrapat, W., Use of LANDSAT-7 ETM+ with ancillary data for soil salinity mapping in northeast Thailand. In Third International Conference on Experimental Mechanics and Third Conference of the Asian Committee on Experimental Mechanics, SPIE Proceedings 5852, International Society for Optics and Photonics, Singapore. 12 April 2005, pp. 708-717; https://doi.org/10.1117/12.621889.

13. Masoud, A. A., Predicting salt abundance in slightly saline soils from Landsat ETM+ imagery using spectral mixture analysis and soil spectrometry. Geoderma, 2014, 217-218, 45-56; https:// doi.org/10.1016/j.geoderma.2013.10.027.

14. Didi, S., Ezzahra, F., Housni, F. E., Toro, H. B. and Najine, A., Mapping of soil salinity using the Landsat 8 image and direct field measurements: a case study of the Tadla Plain, Morocco. J. Indian Soc. Remote Sensing, 2019, 47(7), 1235-1243; https://doi.org/ 10.1007/s12524-019-00979-7. 


\section{RESEARCH ARTICLES}

15. Abuelgasim, A. and Ammad, R., Mapping soil salinity in arid and semi-arid regions using Landsat 8 OLI satellite data. Remote Sensing App. Soc. Environ., 2019, 13, 415-425; https://doi.org/ 10.1016/j.rsase.2018.12.010.

16. Allbed, A., Kumar, L. and Sinha, P., Mapping and modelling spatial variation in soil salinity in the Al Hassa oasis based on remote sensing indicators and regression techniques. Remote Sensing, 2014, 6(2), 1137-1157; https://doi.org/10.3390/rs6021137.

17. Eldeiry, A. A. and Garcia, L. A., Comparison of ordinary kriging, regression kriging, and cokriging techniques to estimate soil salinity using LANDSAT images. J. Irrig. Drain. Eng., 2010, 136(6), 355-364; https://doi:10.1061/(ASCE)IR.1943-4774.0000208.

18. Nouri, H., Borujeni, S. C., Alaghmand, S., Anderson, S. J., Sutton, P. C., Parvazian, S. and Beecham, S., Soil salinity mapping of urban greenery using remote sensing and proximal sensing techniques; the case of Veale Gardens within the Adelaide Parklands. Sustainability, 2018, 10, 2826; https://doi.org/10.3390/ su10082826.

19. Taghadosi, M. M., Hasanlou, M. and Eftekhari, K., Retrieval of soil salinity from Sentinel-2 multispectral imagery. Eur. J. Remote Sensing, 2019, 52(1), 138-154; https://doi.org/10.1080/22797254. 2019.1571870 .

20. Elhag, M., Evaluation of different soil salinity mapping using remote sensing techniques in arid ecosystems, Saudi Arabia. J. Sens., 2016, e7596175; http://dx.doi.org/10.1155/2016/7596175.

21. Rahmati, M. and Hamzehpour, N., Quantitative remote sensing of soil electrical conductivity using ETM+ and ground measured data. Int. J. Remote Sensing, 2017, 38, 123-140; https://doi.org/ 10.1080/01431161.2016.1259681.

22. Alexakis, D. D., Daliakopoulos, I. N., Panagea, I. S. and Tsanis, I. K., Assessing soil salinity using worldview-2 multispectral images in Timpaki, Crete, Greece. Geocarto Int., 2018, 33(4), 321-338; https://doi.org/10.1080/10106049.2016.1250826.

23. Lhissou, R., El Harti, A. and Chokmani, K., Mapping soil salinity in irrigated land using optical remote sensing data. Eurasian $J$. Soil Sci., 2014, 3, 82-88; http://ejss.fess.org/10.18393/ejss.84540.

24. Khan, N. M., Rastoskuev, V. V., Shalina, E. V. and Sato, Y., Mapping salt-affected soils using remote sensing indicators - a simple approach with the use of GIS IDRISI. In Proceedings of the 22nd Asian Conference Remote Sensing, Singapore, 5-9 November 2001; https://crisp.nus.edu.sg/ acrs2001/pdf/206khan.pdf

25. Allbed, A. and Kumar, L., Soil salinity mapping and monitoring in arid and semi-arid regions using remote sensing technology: a review. Adv. Remote Sensing, 2013, 2, 373-385; https://doi:10.4236/ ars.2013.24040.

26. Abbas, A. and Khan, S., Using remote sensing techniques for appraisal of irrigated soil salinity. In MODSIM 2007 International Congress on Modelling and Simulation (eds Oxley, L. and Kulasiri, D.), Modelling and Simulation Society of Austria and New Zealand, December 2007, pp. 2632-2638; https://www.mssanz.org.au/ MODSIM07/papers/46_s60/UsingRemotes60_Abbas_pdf

27. Wang, H., Wang, J. and Liu, G., Spatial regression analysis on the variation of soil salinity in the Yellow River Delta. In the Geoinformatics conference 2007: Geospatial Information Science, International Society for Optics and Photonics, Nanjing, China, 2007, vol. 6753, pp. 67531U; https://doi:10.1117/12.761911.

28. Qu, Y., Jiao, S. and Lin, X., A partial least square regression method to quantitatively retrieve soil salinity using hyper-spectral reflectance data. In Geoinformatics 2008 and Joint Conference on GIS and Built Environment: Classification of Remote Sensing Images. International Society for Optics and Photonics, Proceedings of the SPIE 7147, 71471H (7 November 2008), Guangzhou, China, 2008; https://doi.org/10.1117/12.813254.

29. Cropnuts, How to take a soil sample for field crops? Crop Nutrition Laboratory Services Ltd, Kenya, 2020; https://cropnuts. helpscoutdocs.com/article/879-soil-sampling-for-nutrient-analysis-offield-crops.

30. Fery, M., Choate, J. and Murphy, E., A Guide to Collecting Soil Samples for Farms and Gardens, Oregon State University Extension Service, USA, 2018; https://catalog.extension.oregonstate. edu/sites/catalog/files/project/pdf/ec628.pdf.

31. Franzen, D. W., Soil sampling as a basis for fertilizer application. NDSU Extension, North Dakota State University, USA, 2018; https://www.ag.ndsu.edu/publications/crops/soil-sampling-as-abasis-for-fertilizer-application/sf990.pdf

32. Kargas, G., Londra, P. and Sgoubopoulou, A., Comparison of soil EC values from methods based on 1:1 and 1:5 soil to water ratios and ECe from saturated paste extract based method. Water, 2020, 12, 1010; doi:10.3390/w12041010.

33. Douaoui, A. E. K., Nicolas, H. and Walter, C., Detecting salinity hazards within a semiarid context by means of combining soil and remote-sensing data. Geoderma, 2006, 134, 217-230; https:// doi.org/10.1016/j.geoderma.2005.10.009.

34. Bannari, A., Guedon, A. M., El-Harti, A., Cherkaoui, F. Z. and ElGhmari, A., Characterization of slightly and moderately saline and sodic soils in irrigated agricultural land using simulated data of advanced land imaging (EO-1) sensor. Commun. Soil Sci. Plant Anal., 2008, 39(19-20), 2795-2811; https://doi.org/10.1080/ 00103620802432717.

35. Meti, S., Hanumesh, K., Lakshmi, P. D., Nagaraja, M. S. and Shreepad, V., Sentinel 2 and Landsat- 8 bands sensitivity analysis for mapping of alkaline soil in northern dry zone of Karnataka, India. Int. Arch. Photogramm., Remote Sensing Spat. Inf. Sci., ISPRS-GEOGLAM-ISRS XLII-3/W6; 2019, 307-385; https://www.int-arch-photogramm-remote-sens-spatial-inf-sci.net/ XLII-3-W6/307/2019/isprs-archives-XLII-3-W6-307-2019.pdf

36. Hihi, S., Rabah, Z. B., Bouaziz, M., Chtourou, M. Y. and Bouaziz, S., Prediction of soil salinity using remote sensing tools and linear regression model. Adv. Remote Sensing, 2019, 8(3), 77-88; https://doi.10.4236/ars.2019.83005.

37. Samra, R. M. A. and Ali, R. R., The development of an overlay model to predict soil salinity risks by using remote sensing and GIS techniques: a case study in soils around Idku Lake, Egypt. Environ. Monitor. Assess., 2018, 190, 706-721; https://doi.org/ 10.1007/s10661-018-7079-3.

38. Dehni, A. and Lounis, M., Remote sensing techniques for salt affected soil mapping: application to the Oran region of Algeria. Procedia Eng., 2012, 33, 188-198.

39. Alhammadi, M. S. and Glenn, E. P., Detecting date palm trees health and vegetation greenness change on the eastern coast of the United Arab Emirates using SAVI. Int. J. Remote Sensing, 2008, 29(6), 1745-1765.

40. Abuelgasim, A. and Ammad, R., Mapping soil salinity in arid and semi-arid regions using Landsat 8 OLI satellite data. Remote Sensing Appl. Soc. Environ., 2019; doi:10.1016/j.rsase.2018.12.010.

ACKNOWLEDGEMENTS. We are grateful to the Deanship of Scientific Research, King Saud University, Riyadh for funding this study through the Vice Deanship of Scientific Research Chairs. We also thank Mr Ahmed Alameen, Mr. Mohamed Edrris, and Mr Haroon Edrees for their assistance in soil samples collection and analysis, and Mr Alan King and The Tawdeehiya Farms staff for their support during the field work

Received 30 November 2020; revised accepted 8 April 2021

doi: $10.18520 / \mathrm{cs} / \mathrm{v} 121 / \mathrm{i} 3 / 384-390$ 